\title{
INQUÉRITO EPIDEMIOLÓGICO DE SUPOSTO FOCO DE FEBRE MACULOSA
}

\section{EPIDEMIOLOGICAL SURVEY OF SUPPOSED SPOTTED FEVER OUTBREAK}

\author{
Márcio Eduardo Pereira Martins ${ }^{1^{*}}$ \\ Wilia Marta Elsner Diederichsen Brito ${ }^{2}$ \\ Marcelo Bahia Labruna ${ }^{3}$ \\ Jonas Moraes Filho ${ }^{3}$ \\ Kenia Cristina Sousa-Martins ${ }^{1}$ \\ Rafael Porto Vieira ${ }^{1}$ \\ ${ }^{1}$ Instituto Federal Goiano, Campus Urutaí, Urutaí, GO, Brasil. \\ 2Instituto de Patologia Tropical e Saúde Pública, Universidade Federal de Goiás, Goiânia, GO, Brasil. \\ ${ }^{3}$ Faculdade de Medicina Veterinária e Zootecnia, Universidade de São Paulo, São Paulo, SP, Brasil. \\ *Autor para contato - marcioeduvet@gmail.com
}

\section{Resumo}

O presente estudo objetivou avaliar a suspeita de ocorrência da febre maculosa (FM) em Quirinópolis - GO, por meio de inquérito sorológico em amostras de humanos, cães e equinos e identificação de carrapatos vetores. Em 2007, foram realizadas reações de imunofluorescência indireta (RIFI) para Rickettsia spp. em amostras de sangue colhidas de 28 pessoas do grupo de convívio de um caso suspeito (uma criança de três anos que apresentou sinais de riquetsiose, após exposição a carrapatos). Também foram colhidas amostras de sangue em cinco cães e 42 equinos, havendo soro reagentes somente entre os equinos (28,6\%). Não foi constatada a presença do carrapato Amblyomma cajennense. Sete indivíduos foram reagentes para Rickettsia spp., a maioria desses eram parentes paternos do caso suspeito. Em 2008, na mesma região, foram realizadas RIFI em amostras de 30 humanos sem sinais clínicos de FM e constatou-se 50\% de soro reagentes para Rickettsia spp. Adicionalmente, colheramse amostras de sangue de 24 cães errantes, havendo um cão soropositivo. A evidência sorológica do contato entre bactérias do gênero Rickettsia com habitantes humanos e animais de Quirinópolis indica que a FM ou outra riquetsiose possa estar ocorrendo no Estado de Goiás.

Palavras-chave: A. cajennense; anticorpos; cães; cavalos; humanos; Rickettsia.

\begin{abstract}
This study aimed to evaluate the suspition of spotted fever (SF) occurrence in Quirinopolis city (Goias State) through serological survey in human, dogs and horses samples, and identification of tick vectors. In 2007, indirect immunofluorescence antibody test (IFAT) was carried out for Rickettsia spp. in blood samples taken from 28 persons, related to the suspected case (a 3-year-old child who showed signs of rickettsial disease after exposure to ticks). Also, blood samples were collected from five dogs and 42 horses, from which only there horses (28.6\%) were seropositive. The tick Amblyomma cajennense was not found. Seven humans were reactive to Rickettsia spp., most of them were paternal relatives of the suspected case. In 2008, in the same region, IFAT was performed on 30 human samples without clinical signs of SF and 50\% of them were seropositive for Rickettsia spp. Additionally, blood samples were collected from 24 stray dogs, and one of the animals showed seropositivity. Serologic evidence of the contact between the bacteria of the genus Rickettsia with human and animal inhabitants from Quirinopolis city indicates that the SF or another rickettsial disease may be occurring in Goias State, Brazil.
\end{abstract}


Keywords: A. cajennense; antibodies; dogs; horses; human; Rickettsia.

Enviado em: 12 abril 2015

Aceito em: 18 maio 2016

\section{Introdução}

A febre maculosa (FM) é uma zoonose, de caráter endêmico, transmitida ao homem por carrapato infectado com Rickettsia rickettsii ${ }^{(1)}$. Foi identificada em 1896, no Vale do Rio Snake, Idaho, EUA, e atualmente é notificada em quase todos os estados norte-americanos ${ }^{(2)}$. A partir de 1930, a doença foi identificada focalmente em outros países como Canadá, México, Costa Rica, Panamá, Colômbia, Brasil e Argentina ${ }^{(3-5)}$. No Brasil, a FM é conhecida desde $1929^{(6)}$ e, até o momento, os carrapatos indicados como vetores de Rickettsia sp. pertencem ao gênero Amblyomma: A. aureolatum, presente em animais silvestres, e $A$. cajennense, carrapato estrela ou do cavalo, reconhecido como principal vetor ${ }^{(7)}$.

Segundo dados obtidos no Sistema de Informação de Agravos de Notificação - Sinan Net - do DATASUS do Ministério da Saúde (MS), nos últimos sete anos, período entre 2007 a 2013, foram confirmados 807 casos de FM no Brasil, sendo 71\% na Região Sudeste, com 399 casos registrados em São Paulo, seguido da Região Sul com $26 \%$ dos casos confirmados do país ${ }^{(8)}$.

Aparentemente, a doença tem se disseminado para Estados antes considerados indenes para FM, como é a situação dos Estados das Regiões Nordeste (seis casos - dois na Bahia, três no Ceará e um na Paraíba), Norte (sete casos, sendo um em Rondônia e seis no Tocantins) e Centro-Oeste, que até o presente momento tem ocorrência de FM limitada a nove casos, sendo um caso no DF, três casos no Mato Grosso, dois casos no Mato Grosso do Sul, e três casos de FM confirmados em Goiás até o ano de $2012^{(8,9)}$.

Em humanos, o período de incubação da febre maculosa varia de dois a 14 dias. A doença inicia-se com febre, cefaléia e mialgia intensa. Após dois a seis dias, surgem as manifestações cutâneas (petéquias, máculas), podendo ocorrer edemas nos membros inferiores e oligúria. Sem a devida intervenção medicamentosa, a enfermidade evolui para infecção generalizada, com complicações pulmonares, vasculares, desidratação, choque, coma e morte ${ }^{(10)}$.

Em março de 2009, no Brasil, houve relato de dois cães com febre maculosa por infecção naturalmente adquirida após exposição destes animais em área endêmica para FM em São Paulo. Os cães domiciliares foram levados ao campo e retornaram infestados por carrapatos. Esses animais apresentaram os seguintes sintomas: febre de $40^{\circ} \mathrm{C}$, anorexia, letargia, ataxia, nistagmo, diarréia e vômito. Demais exames confirmaram a etiologia da FM, indicando infecção por $R$. rickettsii ${ }^{(11)}$.

A reação de imunofluorescência indireta (RIFI), método padrão-ouro para a FM segundo a Organização Mundial de Saúde, é preconizada pelo MS como a técnica sorológica para o diagnóstico das riquetsioses ${ }^{(1)}$.

O presente estudo objetivou realizar um levantamento epidemiológico, por meio de inquérito sorológico pela RIFI em amostras de humanos, cães e equinos, e a identificação de carrapatos vetores, em suposto foco de FM registrado em Quirinópolis - GO.

\section{Material e Métodos}

O estudo foi realizado em duas etapas de amostragem: a primeira ocorreu entre fevereiro e março de 2007 e a segunda um ano após, ambas no Município de Quirinópolis-GO, onde aconteceu o caso humano notificado ao MS como suspeito de FM no Estado de Goiás. As amostras foram obtidas considerando-se o perímetro urbano e em três propriedades rurais (PR). Realizou-se questionário epidemiológico fechado de acordo com recomendações de Trhusfield ${ }^{(12)}$, para facilitar a interpretação dos achados laboratoriais, buscando relacioná-los. 
A colheita nos animais foi realizada por Médico Veterinário auxiliado por um técnico da Agência Goiana de Defesa Agropecuária - AGRODEFESA, e a colheita de sangue em seres humanos foi efetuada por uma técnica em enfermagem do Hospital Municipal de Quirinópolis, após ciência e assinatura do termo de consentimento livre e esclarecido. O presente estudo foi consentido pelo Comitê de Ética em Pesquisa Médica Humana e Animal do Hospital das Clínicas da Universidade Federal de Goiás (UFG), sob Protocolo CEPMHA/HC/UFG No 184/06.

Em fevereiro de 2006, uma criança (NFSC) de três anos de idade foi levada ao Hospital Municipal de Quirinópolis - GO, apresentando sinais de febre, com temperatura de $38{ }^{\circ} \mathrm{C}$ e uma mancha rósea no pescoço. A criança foi encaminhada ao Hospital Materno Infantil em Goiânia-GO onde ficou hospitalizada por 53 dias. Exames laboratoriais complementares foram solicitados e duas amostras de sangue, com intervalo de 15 dias, foram colhidas e enviadas à Fundação Oswaldo Cruz (FIOCRUZ), Rio de Janeiro, RJ, de acordo com o protocolo oficial do Ministério da Saúde (MS). O exame confirmou que a criança teve contato com agentes do grupo da febre maculosa, sendo o diagnóstico médico de febre maculosa. Após tratamento com antibióticos específicos, a criança evoluiu para a cura. Este foi o primeiro caso suspeito de FM registrado no município e no Estado de Goiás ${ }^{(13)}$. Reitera-se que o MS considerou o caso NFSC em 2006 como compatível com FM, ficando assim registrado, não sendo dado como caso confirmado porque, apesar dos sinais e sintomas, e como houve eficiência do tratamento, não houve diferença maior ou igual a quatro vezes no título de anticorpos em amostras de soro pareadas.

Dados obtidos com os responsáveis pela criança NFSC, caso suspeito, destacam que o pai era vaqueiro em três fazendas de Quirinópolis e em sua residência havia dois cães infestados por carrapatos. A mãe relatou que a criança sempre "pegava" carrapatos. O pai da criança, trabalhador rural, relatou já ter chegado a sua residência trazendo consigo alguns exemplares de carrapatos na roupa, além disso, declarou que NFSC esteve nas propriedades rurais onde trabalha, tendo contato direto com equinos de montaria.

O sangue foi colhido por meio da venopunção das veias cefálica ou radial nos seres humanos, e radial ou jugular nos cães e equinos. Na primeira amostragem, foram colhidas 28 amostras de sangue humano, sendo 20 de pessoas residentes em área urbana e oito pessoas residentes em meio rural. E importante mencionar que, exceto NFSC, as demais amostras sorológicas foram obtidas de humanos e animais assintomáticos no momento da colheita da amostra.

Dentre os indivíduos coletados na área urbana, estavam NFSC, caso suspeito de ter desenvolvido a enfermidade FM, pai, mãe, avós, tios, tias e primos, considerando-se entes paternos e maternos, e crianças vizinhas conviventes com a NFSC. Foram colhidas ainda amostras de sangue de dois cães criados soltos na residência de NFSC. No meio rural foram colhidas amostras em oito pessoas e cinco cães adultos, SRD, residentes em três propriedades rurais onde NFSC esteve na época precedente ao surgimento dos sinais da enfermidade.

Na segunda etapa de amostragem, realizada em 2008, um ano após a primeira etapa, foram colhidas 30 amostras de sangue humano, oriundas de pacientes do Hospital Municipal de Quirinópolis-GO, de forma aleatória e sem direcionar à possível casuística. Concomitante, foi realizada colheita de amostras de sangue em 24 cães errantes, adultos, SRD, provenientes de um canil mantido por uma ONG que recolhia esses animais da área urbana de Quirinópolis.

Todas as amostras de sangue obtidas foram centrifugadas no Laboratório do Hospital Municipal de Quirinópolis e o soro obtido foi aliquotado em microtubos de $1,5 \mathrm{~mL}$, identificado e estocado em temperatura de $-20{ }^{\circ} \mathrm{C}$. Posteriormente, as amostras de soro foram transportadas acondicionadas em caixa isotérmicas, até o Laboratório de Doenças Parasitárias da Faculdade de Medicina Veterinária e Zootecnia da Universidade de São Paulo, onde foi realizada a sorologia de RIFI.

As amostras de soro foram testadas separadamente frente a extratos brutos de cinco diferentes antígenos riquetsiais: $R$. rickettsii cepa Taiaçu, $R$. parkeri cepa At24, R.amblyommii cepa Ac37, $R$. bellii cepa Mogi ou $R$. rhipicephali cepa HJ5. Essas cepas foram isoladas de carrapatos do Brasil, conforme trabalhos de Horta et al. ${ }^{(14)}$, Labruna et al. ${ }^{(15)}$ e Pinter e Labruna ${ }^{(16)}$. Para obtenção dos antígenos, foram utilizados cultivos de células Vero infectadas com Rickettsia spp. Quando as células atingiram 100\% 
de infecção, os antígenos foram concentrados e fixados em lâminas de vidro contendo 12 pocinhos ${ }^{(17)}$ e armazenadas em freezer com temperatura de $-20^{\circ} \mathrm{C}$ até o momento de uso.

Uma alíquota de soro $(5 \mu \mathrm{L})$ foi diluída (1:64) em solução salina fosfatada tamponada (PBS pH 7,4). Em seguida, o soro diluído $(20 \mu \mathrm{L})$ foi depositado sobre cada poço da lâmina contendo o antígeno (células Vero infectadas com um dos cinco tipos de antígenos riquétsiais) e incubada em câmara úmida, em estufa $\left(37^{\circ} \mathrm{C}\right)$ por 30 minutos. Posteriormente, a lâmina foi mergulhada em solução de lavagem tamponada $(2 \mathrm{X}, 10 \mathrm{~min})$ e deixada para secar em temperatura ambiente. O conjugado espécieespecifico, anticorpo específico anti-espécie (humano, equino ou cão) conjugado com fluoresceína, foi adicionado, em diluições especificas de cada conjugado, em cada poço da lâmina, incubado a $37^{\circ} \mathrm{C}$ por 30 minutos e depois lavado com PBS. A lâmina foi então mergulhada em solução de lavagem acrescida de corante azul de Evans (2X) por 10 minutos, na ausência de luz, e depois foi deixada para secar em temperatura ambiente na ausência de luz. A leitura foi feita ao microscópio de imunofluorescência (Olympus BX60, Tokyo, Japan), em objetiva de 40X.

Os soros reativos na diluição 1:64, apresentando reações de imunocomplexo fluorescente de formatos coco-bacilares em mais que $90 \%$ das células, para qualquer espécie de Rickettsia, foram testados em diluições seriadas na base dois, com início em 1:64, para determinação do título final de reatividade. $\mathrm{O}$ soro que demonstrou para determinada espécie de Rickettsia um título quatro vezes maior que para as demais espécies testadas foi considerado homólogo para a primeira ${ }^{(17,18)}$.

$\mathrm{Na}$ primeira etapa de amostragem, os carrapatos foram colhidos aleatoriamente em 42 equinos parasitados, oriundos de três propriedades rurais, e em dois cães urbanos domiciliares. Na segunda etapa de amostragem, realizada um ano após a primeira, foram colhidos carrapatos em 24 cães errantes provenientes da área urbana de Quirinópolis e também em animais capturados ou abandonados mantidos em canil de uma ONG da cidade.

Os ectoparasitos foram colhidos por todo o corpo dos animais com o auxílio de uma pinça e conservados em álcool isopropílico PA, conforme Sucen ${ }^{(19)}$, até o momento da identificação. Os carrapatos foram identificados de acordo com Battesti et al. ${ }^{(20)}$ no Centro de Parasitologia da Escola de Veterinária da Universidade Federal de Goiás.

\section{Resultados e Discussão}

As pessoas que se dispuseram a participar do presente estudo não apresentavam no momento da coleta de amostras nenhum sinal compatível com febre maculosa; $100 \%$ tinham convívio com cães; das que residiam em área urbana, 100\% relataram irem com frequência ao meio rural e terem contato com equinos; ainda de acordo com dados obtidos com o questionário epidemiológico aplicado, foi comum entre as pessoas o histórico da picada de carrapato em algum momento da vida, mas essas não souberam responder com exatidão se houve febre após esse momento, com exceção do caso de NFSC. A febre após a picada de carrapatos de várias espécies é um sinal clínico comumente relatado nos casos de FM ( $R$. rickettsii) das Américas e outras riquetsioses que ocorrem pelo mundo, tais como febre escaro-nodular ( $R$. conorii), febre africana da picada do carrapato $(R$. africae), tifo do carrapato de Queensland ( $R$. australis), tifo da Ilha Flinders ( $R$. honei), tifo siberiano ou do norte da Ásia ( $R$. sibirica), febre maculosa oriental $(R$. japonica), tibola $(R$. slovaca), Linfangite Expansiva ( $R$. sibirica mongolotimonae), rickettsiose européia $(R$. helvetica) e febre maculosa riquetsiosa $(R \text {. parkeri })^{(1,2,21-26)}$. Histórico da picada de carrapato ou exposição às áreas infestadas de carrapatos ocorre em cerca de 60\% dos casos de Febre Maculosa das Montanhas Rochosas (FMMR) nos EUA ${ }^{(27)}$. Todavia, a transmissão da FM geralmente ocorre quando o artrópode permanece aderido ao hospedeiro por um período de 4-6 horas ${ }^{(28)}$.

De acordo com o questionário epidemiológico, nas três propriedades rurais que NFSC frequentou havia equinos, nos quais NFSC praticava montaria acompanhada, e capivaras que eram frequentemente avistadas nos ambientes onde os equinos eram manejados. As capivaras (Hydrochoerus hydrochaeris), hospedeiros primários de todos os estádios parasitários do Amblyomma cajennense e Amblyomma dubitatum, são consideradas um potencial reservatório de Rickettsia sp $^{(5,19,29-31)}$. 
A sorologia realizada nas amostras colhidas em humanos em fevereiro de 2007 indicou frequência total de soro-reagentes à RIFI para Rickettsia spp. de 25\% (7/28), sendo cinco de indivíduos residentes na área rural e dois na área urbana (Tabela 1). A frequência de $25 \%$ de amostras soro-reagentes foi obtida tanto entre humanos residentes na área rural $(2 / 8)$ quanto em humanos residentes em área urbana $(5 / 20)$.

O resultado da sorologia para Rickettsia spp. nos 28 indivíduos do grupo de convívio de NFSC deu-se da seguinte forma: de oito amostras humanas, oriundas de três propriedades rurais onde NFSC esteve antes da manifestação do quadro patológico, três foram não reagentes, mas duas de cinco amostras da "Propriedade Rural B" foram soropositivas com reações cruzadas para Rickettsia spp.; os pais de NFSC foram soronegativos; as quatro crianças vizinhas de NFSC que conviveram no período prépatente do quadro enfermo foram soronegativas; dos 13 parentes de NFSC, nove foram soronegativos e três entes paternos e um materno foram soropositivos com reações cruzadas para Rickettsia spp.

Tabela 1. Amostras humanas soropositivas à RIFI para Rickettsia spp., colhidas em fevereiro de 2007 , em Quirinópolis-GO

\begin{tabular}{lccccccc}
\hline \multirow{2}{*}{$\begin{array}{l}\text { Amostra } \\
\text { humana }\end{array}$} & \multirow{2}{*}{ Sexo } & Origem & \multicolumn{5}{c}{ Títulos das reações à rifi para Rickettsia spp. ano 2007 } \\
\cline { 4 - 8 } & & & $\begin{array}{c}R \\
\text { rickettsii }\end{array}$ & $\begin{array}{c}R \\
\text { parkeri }\end{array}$ & $\begin{array}{c}R . \\
\text { rhipicephali }\end{array}$ & $\begin{array}{c}R . \\
\text { amblyommii }\end{array}$ & $\begin{array}{c}R . \\
\text { bellii }\end{array}$ \\
\hline NFSC & $\mathrm{F}$ & Urbana & $1: 256$ & $1: 128$ & $1: 64$ & $\mathrm{NR}$ & $\mathrm{NR}$ \\
TioP1 & $\mathrm{M}$ & Urbana & $1: 256$ & $1: 128$ & $1: 64$ & $1: 128$ & $\mathrm{NR}$ \\
AvóP & $\mathrm{F}$ & Urbana & $\mathrm{NR}$ & $1: 64$ & $1: 64$ & $\mathrm{NR}$ & $\mathrm{NR}$ \\
PrimaM & $\mathrm{F}$ & Urbana & $1: 128$ & $1: 64$ & $\mathrm{NR}$ & $\mathrm{NR}$ & $\mathrm{NR}$ \\
TiaP & $\mathrm{F}$ & Urbana & $1: 64$ & $1: 128$ & $\mathrm{NR}$ & $\mathrm{NR}$ & $\mathrm{NR}$ \\
TioP2 & $\mathrm{M}$ & Rural & $1: 128$ & $1: 64$ & $\mathrm{NR}$ & $1: 64$ & $\mathrm{NR}$ \\
Trabalhador & $\mathrm{M}$ & Rural & $1: 128$ & $1: 128$ & $1: 128$ & $1: 256$ & $1: 256$ \\
\hline
\end{tabular}

Legenda: $\mathrm{P}=$ origem paterna; $\mathrm{M}=$ origem materno; $\mathrm{F}=$ feminino; $\mathrm{M}=$ masculino.

O número de amostras humanas soropositivas para Rickettsia spp., em 2007, foi quase na totalidade de entes paternos de NFSC. Isso pode ser explicado pelo fato de a maioria desses indivíduos se dedicarem às atividades rurais, o que seguramente facilitou a exposição, aumentando o risco de contato com bactérias do gênero Rickettsia, diferentemente das demais pessoas que se dedicavam a atividades urbanas. Com relação ao parente materno soropositivo, tratava-se de uma criança prima de NFSC que habita na mesma residência, submetendo-se às mesmas circunstâncias de sobrevivência, riscos e desafios antigênicos.

O soro de NFSC reagiu de forma cruzada para $R$. rickettsii, $R$. parkeri e $R$. rhipicephali (Tabela 1), não havendo diferença significativa para se evidenciar um dos possíveis antígenos riquetsiais, pois os mesmos diferenciaram-se em apenas uma casa de diluição. Dessa forma, baseando-se nos estudos de Horta et al. ${ }^{(17)}$, Labruna et al. ${ }^{(18)}$ e Silva ${ }^{(32)}$, não há como indicar um provável agente causador da resposta imune, pois NFSC pode ter tido contato com ambas as espécies de Rickettsia.

Essa amostra de NFSC foi colhida cerca de um ano após a ocorrência da suspeita clínica de febre maculosa. Como nos dos dois primeiros exames realizados na FIOCRUZ, o soro foi testado somente frente a $R$. rickettsii, havendo dificuldade para uma avaliação mais profunda do caso.

No caso de equinos, constatou-se frequência de 28,6\% (12/42) de animais reagentes para Rickettsia spp à RIFI (Tabela 2) nas amostras colhidas em 2007. Em estudo semelhante concluído em $2014 \mathrm{e}$ realizado no Distrito Federal, Martins ${ }^{(33)}$ constatou $17,2 \%$ de equinos soropositivos para a $R$. rickettsii. Neste estudo, a soropositividade entre os equinos foi encontrada na "Propriedade Rural A", com dois animais reagentes, e na "Propriedade Rural B", com 10 de seus animais reagentes. Dados do questionário epidemiológico realizado revelaram que, nestas propriedades rurais, era frequente a prática de montaria em equinos por NFSC acompanhada de outros adultos. 
Tabela 2. Frequência de soro-positividade à RIFI para Rickettsia spp. das amostras de sangue de equinos, cães e humanos colhidas em propriedades rurais de Quirinópolis-GO, em fevereiro de 2007

\begin{tabular}{cccccccc}
\hline \multicolumn{2}{c}{ LOCAL } & \multicolumn{6}{c}{ Tipo de amostra e frequência da soroconversão à rifi } \\
\hline \multirow{2}{*}{$\begin{array}{c}\text { Propriedade } \\
\text { Rural* }\end{array}$} & Distância & \multicolumn{5}{c}{ Soro sanguíneo } \\
\cline { 3 - 8 } & $\mathbf{k m}^{* *}$ & \multicolumn{2}{c}{ Equinos } & \multicolumn{2}{c}{ Cães } & \multicolumn{2}{c}{ Humanos } \\
\cline { 3 - 8 } & & Total & Reagente & Total & Reagente & Total & Reagente \\
\hline A & 8 & 8 & 2 & 2 & 0 & 2 & 0 \\
B & 25 & 20 & 10 & 2 & 0 & 5 & 2 \\
C & 50 & 14 & 0 & 1 & 0 & 1 & 0 \\
\hline
\end{tabular}

*Propriedades rurais com equinos onde NFSC esteve antes de manifestar sinais de enfermidade. ${ }^{* *}$ Relativo à distância da propriedade rural até a área urbana de Quirinópolis.

Um estudo realizado em São Paulo, com humanos, cães e cavalos, apontou o cavalo como excelente animal sentinela para febre maculosa, demonstrando que cavalos soropositivos são um forte indicador de enfermidade nas áreas onde os seres humanos são expostos ao carrapato vetor ${ }^{(32)}$.

Dos 10 de equinos soropositivos da "Propriedade Rural B", seis foram soro-especificos para $R$. rickettsii e quatro apresentaram reação cruzada para $R$. rickettsii e $R$. parkeri (Tabela 3). Nesta propriedade, das duas amostras humanas soropositivas, uma era de um dos tios paternos de NFSC e outra de um trabalhador rural responsável pelo manejo dos equinos da propriedade. Sangioni et al. ${ }^{(34)}$ observaram que nenhuma das 66 amostras de soro de humanos oriundos de seis fazendas de áreas endêmicas e não endêmicas para FM submetidas à RIFI para um único antígeno testado de $R$. rickettsii reagiu positivamente. $\mathrm{O}$ referido estudo diferencia-se do presente, pois nele somente as amostras de equinos e cães da área endêmica para FM reagiram positivamente, já em Goiás, entre as amostras colhidas, houve humanos e equinos soro-reagentes e essas amostras foram oriundas de área considerada ainda indene para FM.

A reação específica de amostras equinas contra $R$. rickettsii é a primeira evidência de que essa bactéria esteja circulando em Goiás, Estado que, antes do presente estudo, era considerado indene à esta bactéria. Provavelmente, esta bactéria esteja sendo mantida em ciclo silvestre por algum animal adaptado às condições de hospedeiro.

FREITAS $^{(35)}$, objetivando obter informações sobre a epidemiologia da FMB em São José dos Pinhais, PR, onde foi registrado o primeiro caso da doença em humano neste Estado, analisou por RIFI 75 soros de equinos frente à $R$. rickettsii e a $R$. parkeri, no período de abril de 2005 a junho de 2006, e encontrou sete animais $(9,33 \%)$ com títulos variando entre 64 a 1024, reagentes apenas à $R$. rickettsii. Considerando-se que o equino é um animal sentinela para FM, admitindo-se que possam percorrer grandes distâncias ou até mesmo serem livremente comercializados, podendo carrear vetores infectados, esses animais podem se tornar grandes disseminadores de FM.

$\mathrm{Na}$ "Propriedade Rural A", em uma amostra equina reagente à RIFI para as cinco espécies de Rickettsia pesquisadas, foi encontrado o mais expressivo título de anticorpos anti-riquetsiais do presente estudo. A reação cruzada na "amostra equina 5", estabelecida sorologicamente entre $R$. rickettsii, $R$. parkeri e $R$. bellii, apresentou título quatro vezes maior que os demais. Nesta propriedade não houve humanos ou cães soropositivos para Rickettsia spp.

No caso de reações cruzadas como na "amostra equina 5" da "Propriedade Rural A", não se pode concluir qual a espécie de Rickettsia que esteve ou está circulando na área estuda, já que reagiu para vários antígenos. $\mathrm{O}$ expressivo título obtido nesta amostra equina sugere a possibilidade desse equino ter sofrido infecção simultânea pelas três espécies de Rickettsia: R.rickettsii, R. parkeri e R. bellii. Em 2002, na Virgínia, EUA, a R. parkeri foi incriminada como patogênica para humanos ${ }^{(36)}$.

A FM causada por $R$. parkeri caracteriza-se por um curso não grave, sem letalidade registrada e tende a diferenciar-se clinicamente da doença causada por $R$. rickettsii, por apresentar linfadenopatia e uma lesão papular típica ("tache noir") no sítio de fixação do carrapato ${ }^{(34,37) .}$ 
Semelhante ao ocorrido neste estudo, um equino do município de Piracicaba, área endêmica para FM em São Paulo, reagiu de forma cruzada para $R$. rickettsii, $R$. parkeri, $R$. felis e $R$. belii, mas indicou a homologia da reação para $R$. parkeri com título $1: 4096^{(38)}$. Já quanto a $R$. bellii, atualmente a riquétsia mais prevalente em carrapatos no Brasil ${ }^{(15,16)}$, não há evidência que comprove a patogenicidade dessa bactéria para humanos ou animais ${ }^{(18)}$.

Das 30 amostras de soro colhidas de humanos, residentes em meio urbano do município de Quirinópolis, $50 \%(15 / 30)$ reagiram para algum tipo de antígeno riquétsial (Tabela 4). Essa frequência de humanos reagentes pode ser considerada alta, comparativamente aos achados de Pinter et al. ${ }^{(39)}$ que, avaliaram, por RIFI para quatro riquétsias, amostras de 25 cães e 35 humanos provenientes de área endêmica para FM no Estado de São Paulo (Estado de maior ocorrência de FM no país), onde o carrapato A. aureolatum é o principal vetor de FM. Esses autores constataram frequência de $64 \%$ e $2,8 \%$ de soropositivos para cães e humanos, respectivamente, e atribuíram à $R$. rickettsii a responsabilidade antigênica da resposta imune encontrada, por meio dos altos títulos obtidos, em amostras de sete cães e um humano.

Tabela 3. Amostras equinas soropositivas à RIFI para Rickettsia spp., colhidas em fevereiro de 2007, em Quirinópolis-GO

\begin{tabular}{ccccccc}
\hline Amostra & Propriedade & \multicolumn{5}{c}{ Títulos das reações à rifi para Rickettsia spp. Ano 2007 } \\
\cline { 3 - 7 } Equina & Rural & R. rickettsii & R. parkeri & R. rhipicephali & R. amblyommii & R. bellii \\
\hline 1 & $\mathrm{~A}$ & $1: 128$ & $1: 64$ & $\mathrm{NR}$ & $\mathrm{NR}$ & $\mathrm{NR}$ \\
5 & $\mathrm{~A}$ & $1: 4096$ & $1: 4096$ & $1: 128$ & $1: 64$ & $1: 4096$ \\
2 & $\mathrm{~B}$ & $1: 128$ & $\mathrm{NR}$ & $\mathrm{NR}$ & $\mathrm{NR}$ & $\mathrm{NR}$ \\
4 & $\mathrm{~B}$ & $1: 256$ & $1: 64$ & $\mathrm{NR}$ & $\mathrm{NR}$ & $\mathrm{NR}$ \\
5 & $\mathrm{~B}$ & $1: 256$ & $\mathrm{NR}$ & $\mathrm{NR}$ & $\mathrm{NR}$ & $\mathrm{NR}$ \\
8 & $\mathrm{~B}$ & $1: 128$ & $\mathrm{NR}$ & $\mathrm{NR}$ & $\mathrm{NR}$ & $\mathrm{NR}$ \\
9 & $\mathrm{~B}$ & $1: 512$ & $1: 256$ & $\mathrm{NR}$ & $\mathrm{NR}$ & $\mathrm{NR}$ \\
12 & $\mathrm{~B}$ & $1: 64$ & $1: 128$ & $\mathrm{NR}$ & $\mathrm{NR}$ & $\mathrm{NR}$ \\
15 & $\mathrm{~B}$ & $1: 64$ & $\mathrm{NR}$ & $\mathrm{NR}$ & $\mathrm{NR}$ & $\mathrm{NR}$ \\
16 & $\mathrm{~B}$ & $1: 128$ & $1: 64$ & $\mathrm{NR}$ & $\mathrm{NR}$ & $\mathrm{NR}$ \\
18 & $\mathrm{~B}$ & $1: 256$ & $1: 64$ & $\mathrm{NR}$ & $\mathrm{NR}$ & $1: 256$ \\
19 & $\mathrm{~B}$ & $1: 256$ & $\mathrm{NR}$ & $\mathrm{NR}$ & $\mathrm{NR}$ & $\mathrm{NR}$ \\
\hline
\end{tabular}

Tabela 4. Amostras soropositivas à RIFI para Rickettsia spp., em humanos urbanos, colhidas em fevereiro de 2008, em Quirinópolis-GO

\begin{tabular}{|c|c|c|c|c|c|c|}
\hline \multirow{2}{*}{$\begin{array}{l}\text { Amostra } \\
\text { humana }\end{array}$} & \multirow{2}{*}{ Sexo } & \multicolumn{5}{|c|}{ TÍTULOS DAS REAC̣ÕES À RIFI PARA Rickettsia spp. Ano 2008} \\
\hline & & R. rickettsii & R. parkeri & R. rhipicephali & R. amblyommii & R. bellii \\
\hline 4 & $\mathrm{M}$ & $1: 128$ & $1: 128$ & NR & NR & NR \\
\hline 5 & F & $1: 256$ & $1: 128$ & NR & NR & NR \\
\hline 8 & $\mathrm{M}$ & $1: 128$ & $1: 128$ & NR & NR & NR \\
\hline 12 & F & $1: 64$ & NR & $1: 64$ & $1: 64$ & NR \\
\hline 13 & $\mathrm{M}$ & $1: 64$ & $1: 64$ & $1: 128$ & NR & NR \\
\hline 14 & $\mathrm{M}$ & $1: 256$ & $1: 128$ & NR & NR & NR \\
\hline 15 & F & NR & NR & $1: 64$ & NR & NR \\
\hline 16 & $\mathrm{M}$ & $1: 512$ & $1: 256$ & $1: 128$ & $1: 64$ & NR \\
\hline 17 & $\mathrm{M}$ & $1: 256$ & $1: 128$ & $1: 64$ & $1: 64$ & $1: 64$ \\
\hline 18 & F & $1: 128$ & NR & NR & NR & $1: 64$ \\
\hline 20 & M & $1: 128$ & NR & $1: 64$ & $1: 64$ & $1: 128$ \\
\hline 21 & F & $1: 128$ & $1: 64$ & $1: 128$ & $1: 64$ & $1: 64$ \\
\hline 22 & $\mathrm{~F}$ & $1: 128$ & $1: 64$ & $1: 256$ & $1: 64$ & NR \\
\hline 23 & $\mathrm{M}$ & $1: 256$ & $1: 128$ & $1: 256$ & $1: 64$ & NR \\
\hline 26 & $\mathrm{M}$ & $1: 128$ & $1: 64$ & $1: 128$ & $1: 128$ & $1: 128$ \\
\hline
\end{tabular}

Legenda: $\mathrm{M}=$ masculino; $\mathrm{F}=$ feminino. 
Já em Quirinópolis, somente uma das amostras humanas foi soro-reagente específica para $R$. rhipicephali, porém com título de 1:64. Embora o título de anticorpos obtido na amostra humana que reagiu para $R$. rhipicephali tenha sido o "cut-off" da soro-reação, esse achado constitui o primeiro indício da presença desta espécie de Rickettsia no Estado de Goiás. Apesar de a R. rhipicephali estar sendo isolada em carrapatos $D$. variabilis na Califórnia, nos EUA, região endêmica para FMMR ${ }^{(40)}$ e em Monte Negro, Amazonas, no Brasil, e de já ter sido evidenciada sorologicamente em amostras de cães testados frente a seis espécies de Rickettsia ${ }^{(18)}$, ainda não há na literatura prova científica que a indique como patogênica para seres humanos.

Dentre as 30 amostras humanas de 2008 , em que a composição foi de $1 / 2$ por gênero, $50 \%$ foram soropositivos à RIFI para Rickettsia spp. e, destes, $40 \%$ eram mulheres e $60 \%$ eram homens. De acordo com o Ministério da Saúde ${ }^{(10)} 73 \%$ das pessoas acometidas pela FM são do sexo masculino e $27 \%$ do sexo feminino; informações também observadas por NASSER et al. ${ }^{(31)}$

Em meio às sororreações humanas das amostras coletadas em 2008, houve resposta para todas as cinco espécies de Rickettsia. Os maiores títulos foram para $R$. rickettsii; no entanto, com exceção de uma soroconversão para $R$. rhipicephali, os demais soropositivos reagiram de forma cruzada para as espécies de Rickettsia estudadas e os títulos dessas reações não foram homólogos a um determinado agente, assim como sugere Horta et al. ${ }^{(17)}$, pois a diferença entre títulos foi quatro vezes ou mais. Sabidamente houve contato entre esses indivíduos e a(s) bactéria(s) do grupo da febre maculosa, mas não se pode diagnosticar com precisão um antígeno responsável pela resposta antigênica observada.

Neste estudo, foi observado que de um ano para outro houve aumento da frequência de humanos soropositivos à RIFI para Rickettsia spp., já que em 2007 foi de 25\% (7/28) e em 2008 foi de 50\% $(15 / 30)$.

As cinco amostras de sangue dos cães de área rural (Tabela 2) e as duas de área urbana, colhidas em fevereiro de 2007, foram soronegativas à RIFI para Rickettsia spp. Esse achado não traz evidências de que os referidos animais tenham sido prováveis fontes de infecção de Rickettsia sp. para NFSC e demais humanos de seu grupo de convívio.

Dentre as 24 amostras de soro de cães urbanos, colhidas em fevereiro de 2008, uma amostra (4,16\%) foi reagente de forma cruzada à RIFI. Houve sororeatividade para $R$. rickettsii (1:512), $R$. parkeri (1:128), $R$. amblyommii (1:64) e $R$. rhipicephali (1:64). A sororreação de título 1:512 foi considerada homologa para $R$. rickettsii (diferença quatro vezes entre os dois maiores títulos), o que gera fortes indícios da presença deste agente infeccioso em Goiás. Estes cães eram animais errantes, animais que passaram parte de sua vida sobrevivendo livres pelas ruas da cidade e que, no momento da colheita das amostras de sangue, eram mantidos por uma ONG em um canil de recolhimento.

Essa amostra canina soropositiva para $R$. rickettsii em Quirinópolis, Goiás, é altamente representativa se comparada aos resultados de Silva ${ }^{(32)}$, que também analisou por RIFI amostras de sangue de 453 cães de Belo Horizonte (tendo como referência uma estimativa da população canina do CCZ de Belo Horizonte), Minas Gerais, estado detentor do segundo maior índice de ocorrência e incidência de febre maculosa, obtendo prevalência de $0,66 \%$ de positividade com reações cruzadas, frente às mesmas espécies de Rickettsia aqui testadas. Semelhante ao ocorrido no presente estudo, somente uma das amostras caninas de Silva ${ }^{(32)}$ teve título alto o suficiente para indicar a $R$. rickettsii como provável agente infeccioso causador de tal resposta imune.

Dados coletados com o questionário epidemiológico revelaram que, na residência de NFSC, havia dois cães adultos, SRD, infestados de carrapatos. As amostras de sangue destes animais foram soronegativas à RIFI para Rickettsia spp. e os 20 carrapatos adultos colhidos nestes animais foram caracterizados como pertencentes a espécie Rhipicephalus sanguineus. Carrapatos $R$. sanguineus, comum em cães, são considerados possíveis vetores de riquetsiose no México $^{(2)}$.

Os 76 carrapatos adultos colhidos nos 42 equinos das três propriedades rurais amostradas foram caracterizados, de acordo com Battesti et al. ${ }^{(20)}$, como pertencentes a duas espécies (Tabela 5). O $A$. cajennense, considerado principal vetor de FM no Brasil, não foi encontrado no presente estudo. Outro estudo em que se constataram soro-reagentes aos antígenos em questão, os pesquisadores, apesar de terem verificado a presença de vetores, não detectaram DNA de Rickettsia spp. nos ácaros capturados ${ }^{(37)}$. 
Tabela 5. Carrapatos colhidos em equinos parasitados no período de fevereiro a março de 2007, em três propriedades rurais de Quirinópolis, Goiás

\begin{tabular}{|c|c|c|c|c|c|c|c|c|c|c|}
\hline \multirow{4}{*}{ Propriedade } & \multicolumn{10}{|c|}{ Carrapatos } \\
\hline & \multirow{2}{*}{\multicolumn{3}{|c|}{ Total por estádio }} & \multicolumn{7}{|c|}{ Total por Espécie/sexo/propriedade } \\
\hline & & & & \multicolumn{2}{|c|}{ R.(B.)microplus } & \multicolumn{2}{|c|}{ D. nitens } & \multicolumn{2}{|c|}{ A. cajennense } & \multirow[b]{2}{*}{ Total } \\
\hline & larva & ninfa & adulto & $\mathbf{F}$ & $\mathbf{M}$ & $\mathbf{F}$ & $\mathbf{M}$ & $\mathbf{F}$ & $\mathbf{M}$ & \\
\hline $\mathbf{A}$ & 0 & 0 & 0 & 0 & 0 & 0 & 0 & 0 & 0 & 0 \\
\hline B & 3 & 1 & 9 & 6 & 2 & 0 & 1 & 0 & 0 & 13 \\
\hline $\mathbf{C}$ & 0 & 5 & 67 & 0 & 0 & 49 & 18 & 0 & 0 & 72 \\
\hline Total & 3 & 6 & 76 & 6 & 2 & 49 & 19 & 0 & 0 & 85 \\
\hline
\end{tabular}

Legenda: $R$.(B.) microplus $=$ Rhipicephalus (Boophilus) microplus; D. nitens $=$ Dermacentor nitens; A. cajennense $=$ Amblyomma cajennense.

Segundo Pinter et al.(7), no Brasil, os carrapatos Rhipicephalus (Boophilus) microplus e Dermacentor nitens não têm importância na epidemiologia da $R$. rickettsii. Por outro lado, recentemente no Estado do Arizona, EUA, o carrapato $R$. sanguineus foi indicado como possível vetor de $\mathrm{FM}^{(41)}$ após exemplares serem colhidos do cão que pertencia a uma pessoa que contraiu a enfermidade depois da picada do carrapato. A presença de $R$. rickettsii foi detectada por PCR e isolada em cultura celular. Desta forma, é possível que esta espécie tenha algum papel, ainda a ser comprovado, como vetor de $R$. rickettsii para humanos no Brasil.

Por ocasião do presente estudo, uma amostra de sangue da criança NFSC foi colhida um ano (fevereiro/2007) após a suspeita da enfermidade, ocorrida em fevereiro de 2006. Esta foi a terceira amostra de NFSC soro-reagente ao teste de RIFI para $R$. rickettsii. O Ministério da Saúde considerou o caso da criança NFSC como compatível com Febre Maculosa, caracterizando-o como quadro de riquetsiose, diante do resultado gerado pela FIOCRUZ, com provas sorológicas pareadas com ambos os títulos reagentes a $1: 64^{(42,43)}$.

Neste estudo, o titulo de anticorpos contra $R$. rickettsii na amostra de soro da criança NFSC foi de 1:256; no entanto, a amostra reagiu de forma cruzada para mais duas outras espécies de Rickettsia, das quais somente a espécie $R$. parkeri apresenta evidência de patogenicidade para seres humanos descrita na literatura, porém de forma mais branda ${ }^{(36,44)}$.

No Distrito Federal, dois casos de FM, um em 2005 e outro em 2006, foram confirmados pelo Ministério da Saúde ${ }^{(45)}$, mas não há informações de que sejam casos autóctones. Até a data de realização do presente estudo, compreendida entre 2006 e 2009, de fato a ocorrência da FM ainda não havia sido confirmada no Estado de Goiás, já que no resultado da RIFI realizado nas amostras de sangue pareadas colhidas de NFSC teria que ter havido uma diferença mínima de $4 \mathrm{X}$ entre os títulos obtidos nestas duas amostras contemporâneas de NFSC, indicando infecção ativa, para que se reconhecesse oficialmente a ocorrência ${ }^{(1)}$. Todavia, o caso de NFSC somado aos resultados da análise sorológica pela RIFI aqui realizada, detectando a presença de anticorpos anti-riquetsiais com títulos significativos nas amostras de soro humano e animal de Quirinópolis, constituem indícios da presença de agentes do grupo das FM no Estado ${ }^{(46)}$.

Além de o principal vetor associado à FM (A. cajennense) estar presente no Estado de Goiás ${ }^{(47)}$, a constatação de anticorpos anti-riquetsiais verificados, do presente estudo, em humanos e animais, há a proximidade com Estados limítrofes à Goiás, como Minas Gerais e São Paulo (onde ocorrem a maioria dos casos reportados ao MS e onde a doença é mais letal). Tais fatores permitem pensar que haja ausência de diagnóstico clínico ${ }^{(33,42,47)}$, já que se trata de enfermidade infecciosa que não apresenta sinais patognomônicos e que pode ser confundida com outras enfermidades ${ }^{(48)}$. 


\section{Conclusões}

Mesmo sem a constatação dos potenciais vetores da FM, os títulos de anticorpos aqui constatados constituem evidência sorológica do contato entre a bactéria $R$. rickettsii, e outras espécies de Rickettsia, com habitantes humanos e animais de Quirinópolis, indicando que a febre maculosa, ou outra riquetsiose antigenicamente semelhante, provavelmente estava ocorrendo em Goiás, sem que houvesse diagnóstico, e com isso, sem que houvesse registro de caso confirmado.

\section{Referências}

1.BRASIL. Ministério da Saúde. Guia de vigilância epidemiológica. MS, Secretaria de Vigilância em Saúde. 7ed. Brasília: MS; 2009. 816p. ISBN 978-85-334-1632-1.

2.Diagnosis and Management of Tickborne Rickettsial Diseases. Morbidity and Mortality Weekly Report. Centers for Disease Control and Prevention, Atlanta-GA: CDC, 2006; 55 (RR-4): 1-36. [Acesso 24 jun 2016]. Disponível em: http://www.cdc.gov/mmwr/PDF/rr/rr5504.pdf

3.Acha PN, Szyfres B. Zoonosis y enfermedades transmisibles comunes al hombre y a los animales. 2nd ed., Washington, Distrito de Columbia: Organizacion Panamericana de la Salud, 1986. 989 p.

4.OPAS - Organização Pan-Americana da Saúde. Organização Mundial da Saúde. Consulta de especialistas OPAS/OMS sobre rickettsioses nas Américas - Relatório Final. Ouro Preto, Minas Gerais, Brasil,18 - 19 de setembro de 2004. [Acesso 24 maio 2014]. Disponível em: http://bvs.panaftosa.org.br/textoc/Reuniao-rickettport-rev.pdf

5.SUCEN. Superintendência de Controle de Endemias-SP. Febre Maculosa. [Acesso 21 jun 2016]. Disponível em: http://www.saude.sp.gov.br/sucen-superintendencia-de-controle-de-endemias/programas/febre-maculosa/ doenca

6.Piza JT, Meyer JR, Gomes LS. Tipho exanthematico em São Paulo. Soc. Impress. Paulista, São Paulo, 1932.

7.Pinter A, Horta MC, Labruna MB. Febre Maculosa - Informe Técnico II/Centro de Vigilância Epidemiológica "Prof. Alexandre Vranjac". [Acesso 21 jun 2016]. Disponível em: http://www.saude.sp.gov.br/resources/ses/ perfil/gestor/documentos-tecnicos/informes-tecnicos/informe tecnico sobre febre maculosa.pdf

8.BRASIL, 2016. DATASUS/FEBRE MACULOSA - Casos confirmados notificados no Sistema de Informação de Agravos de Notificação - SinanNet. [Acesso 21 jun 2016]. Disponível em: http://tabnet.datasus.gov.br/cgi/ deftohtm.exe?sinannet/cnv/febremaculosabr.def

9.BRASIL, 2015. Casos confirmados de Febre maculosa. Brasil, Grandes Regiões e Unidades Federadas. 1997 a 2014*. [Acesso 12 abril 2015]. Disponível em: http://portalsaude.saude.gov.br/images/pdf/2014/maio/26/ anexo-FebreMaculosa.pdf

10.BRASIL. Ministério da Saúde. Profissional de gestor. Vigilância. Glossário de doenças. Febre Maculosa. [Acesso 21 jun 2016]. Disponível em: http://portalsaude.saude.gov.br/index.php/o-ministerio/principal/ secretarias/svs/febre-maculosa

11.Labruna MB, Kamakura O, Moraes-Filho J, Horta MC, Pacheco RC. Rocky Mountain Spotted Fever in Dogs, Brazil. Emerging Infectious Diseases, 2009; 15(3):458-460.

12.Trhusfield MV. Veterinary Epidemiology. Oxford: BLACKWELL SCIENCE, 3ed., 2005. 600p. 
13.Oliveira VAC. Comunicação pessoal - Superintendência de Políticas de Atenção Integral à Saúde, da Secretaria de Estado da Saúde, Goiás, 2006.

14.Horta M C, Labruna MB, Pinter A, Linardi PM, Schumaker TTS. Rickettsia infection in five areas of the state of São Paulo, Brazil. Mem. Inst. Oswaldo Cruz, 2005; 102(7): 793-801.

15.Labruna MB, Whitworth T. Rickettsia bellii and Rickettsia amblyommii in Amblyomma ticks from the state of Rondonia, Western Amazon, Brazil. J. Med. Entomol., 2004; 41: 1073-81.

16.Pinter A, Labruna MB. Isolation of Rickettsia rickettsii and Rickettsia bellii in cell culture from the tick Amblyomma aureolatum in Brazil. Ann. N. Y. Acad. Sci., 2006; 1078: 523-9.

17.Horta MC, Labruna MB, Sangioni LA, Vianna MCB, Gennari MS, Galvao MAM. Prevalence of antibodies to spotted fever group rickettsiae in humans and domestic animals in a Brazilian Spotted fever endemic area in the state of Sao Paulo, Brazil: serological evidence for infection by Rickettsia rickettsii and another spotted fever group rickettsia. Am J Trop Med Hyg, 2004; 71: 93-7.

18.Labruna MB, Horta MC, Aguiar DM, Cavalcante GT, Pinter A, Gennari SM, Camargo LMA. Prevalence of Rickettsia Infection in Dogs from the Urban and Rural Areas of Monte Negro Municipality, Western Amazon, Brazil. Vect-Bor.Zoon. Dis. 2007; 7(2):249-255.

19.SUCEN. Superintendência de Controle de Endemias-SP. Manual de Vigilância Acarológica, São Paulo: SUCEN. [Acesso 21 jun 2016]. Disponível em: http://www.saude.sp.gov.br/resources/sucen/homepage/ downloads/arquivos-de-febre-maculosa/manual_vig_acarologica.pdf

20.Battesti DMB, Arzua M, Bechara GH. Carrapatos de importância médico-veterinária da Região Neotropical: um guia ilustrado para identificação de espécies. São Paulo: VOX/ICTTD-3/Butantan, 2006, 223p.

21.Hoogstraal H. Argasid and Nuttalliellid ticks as parasits and vectors. Advance Parasitology, 1985; 1 (24): $35-238$.

22.Raoult D, Roux V. Rickettioses as paradigms of new or emerging infectious diseases. Clinical Microbiology Reviews. 1997; 10(4):694-719.

23.Beati, L, Raoult, D. Mediterranean Spotted Fever and other Spotted Fever Group Rickettsiae. In: Palmer, RS, Soulsby L, Simpson DIH. Zooneses, Oxford: University Press, 1998; 217-240.

24.Fournier PE, Grunnenberger F, Jaulhac B, Gastinger G, Raoul D. Evidence of Rickettsia helvetica infection in humans. Eastern, France. Emerg. Infec. Dis. 2000; 6(4):289-392.

25.Lakos A. Tick-borne lymphadenopathy (TIBOLA). Wien Klin Wochenschr, Áustria. [Acesso 21 jun 2016]. Disponível em: https://www.researchgate.net/publication/8220907 Tick-borne lymphadenopathy TIBOLA

26.Uslan DZ, Sia IG. African Tick-Bite Fever. Mayo Clinic Proceedings, v.79, n. 8, p.1007, 2004. [Acesso 21 jun 2016]. Disponível em: http://www.mayoclinicproceedings.org/article/S0025-6196(11)62574-3/pdf

27.CDC - Centers for Disease Control and Prevention. Rocky Mountain Spotted Fever. Statistics. [Acesso 21 jun 2016]. Disponível em: http://www.cdc.gov/rmsf/stats/index.html

28.BRASIL. Ministério da Saúde. Guia de vigilância epidemiológica. Ministério da Saúde, Secretaria de Vigilância em Saúde. 7ed. Brasília: Ministério da Saúde, 813p, 2009. [Acesso 24 jun 2016]. Disponível em: http://bvsms.saude.gov.br/bvs/publicacoes/guia_vigilancia_epidemiologica_7ed.pdf

29.Nogueira MF, Cruz TF. Doenças da Capivara. 1 ed. Corumbá, MS: Embrapa Pantanal, 2007, 74p. Disponível no site: http://www.cpap.embrapa.br/publicacoes/download.php?arq_pdf=Livro030 
30.Souza CE, Moraes-Filho J, Ogrzewalska M, Uchoa FC, Horta MC, Souza SS, Borba, RC, Labruna MB. Experimental infection of capybaras Hydrochoerus hydrochaeris by Rickettsia rickettsii and evaluation of the transmission of the infection to ticks Amblyomma cajennense. Vet. Parasitol. 2009; 161: 116-121. doi:10.1016/j. vetpar.2008.12.010

31.Nasser JT, Lana RC, Silva CMS, Lourenço RW, Cunha e Silva DC, Donalísio MR. Urbanização da febre maculosa brasileira em município da região Sudeste: epidemiologia e distribuição espacial. Rev Bras Epidemiol, 2015 abr-jun; 18(2): 299-312.

32. Silva ME, Ribeiro RR, Costa JO, Moraes-Filho J, Pacheco RC, Labruna MB. Prevalência de anticorpos antiRickettsia spp. em cães da cidade de Belo Horizonte, MG. Arq. Bras. Med. Vet. e Zootec. 2010; 62(4):1007-10.

33.Martins GP. Detecção sorológica de riquétsias do grupo da febre maculosa e levantamento acarológico em equinos no Distrito Federal, Brasil [Dissertação]. Brasília: Universidade de Brasília; 2014. [Acesso 23 jun 2016]. Disponível em: http://repositorio.unb.br/bitstream/10482/16582/1/2014_GustavoPereiraMartins.pdf

34. Sangioni LA, Horta MC, Vianna MCB, Gennari SM, Soares RM, Galvão MAM, Schumaker TTS, Ferreira F, Vidotto O, Labruna MB. Rickettsial lnfection in Animals and Brazilian Spotted Fever Endemicity. Emerg. Infect. Dis. 2005; 11(2):265-270.

35.Freitas MCDO. Detecção de rickettsias do grupo febre maculosa em cães e equinos em São José dos Pinhais, PR. [Tese] Curitiba: Universidade Federal do Paraná, 2007. [Acesso 23 jun 2016]. Disponível em: http://acervodigital.ufpr.br/handle/1884/13858

36.Paddock CD, Sumner JW, Comer JA, Zaki SR, Goldsmith CS, Goddard J, Mclellan SL, Tamminga CL, Ohl CA. Rickettsia parkeri: a newly recognized cause of spotted fever rickettsiosis in the United States. Clin Infect Dis. 2004; 38(6):805-11.

37.Martins MEP, Brito WMED, Labruna MB, Moraes-Filho J. Identificação e pesquisa de Rickettsia spp. em carrapatos colhidos em cães e equinos de Quirinópolis, Goiás, Brasil. Multi-Science J. 2015; 1(1):120-127. [Acesso 24 jun 2016]. Disponível em: https:/www.ifgoiano.edu.br/periodicos/index.php/multiscience/article/ view $/ 58 / 33$

38.Horta MC, Labruna MB, Pinter A, Linardi PM, Schumaker TTS. Rickettsia infection in five areas of the state of São Paulo, Brazil. Mem. Inst. Oswaldo Cruz, 2007; 102(7):793-801.

39.Pinter A, Horta MC, Pacheco RC, Moraes-Filho J, Labruna MB. Serosurvey of Rickettsia spp. in dogs and humans from an endemic area for Brazilian spotted fever in the State of São Paulo, Brazil. Cad. Saúde Pública, Rio de Janeiro, 2008; 24(2):247-252.

40.Wikswo ME, Hu R, Dasch GA, Krueger L, Arugay A, Jones K, Hess B, Bennett S, Kramer V, Eremeeva ME. Detection and Identification of Spotted Fever Group Rickettsiae in Dermacentor Species from Southern California. J. Med. Entom. 2008; 45(3):509-516.

41.Demma LJ, Traeger MS, Nicholson WL, Paddock CD, Blau DM, Eremeeva ME, Dasch GA, Levin ML, Singleton JJR, Zaki SR, Cheek JE. Rocky Mountain spotted fever from an unexpected tick vector in Arizona. N Engl J Med, 2005; 353(6):551-553.

42.Calic SB, Rocha CMBM, Bruhn FRP, Barros RA, Leite RC. Fatores associados aos casos de Febre Maculosa Brasileira frente aos suspeitos não confirmados, Minas Gerais, 1995 a 2002*. Rev. Bras. Med. Vet., 2015 jul/ set; 37(3):239-244.

43.Martins EC. Comunicação pessoal, fornecida pela Gerência Técnica de FM do MS-Brasília, durante o "5 Seminário de Doenças Transmitidas por Carrapatos", realizado pela Secretaria de Estado da Saúde do Estado de São Paulo/SUCEN/Regional de Campinas-SP e Unicamp, Campinas, 2007.

44.Silveira I, Martins TF, Olegário MM, Peterka C, Guedes E, Ferreira F, Labrbuna MB. Rickettsial infection 
in animals, humans and ticks in Pauliceia, Brazil. Zoon. Pub. Health, 2015; 62(7):525-533.

45.BRASIL. Ministério da Saúde. Casos confirmados de febre maculosa. Brasil, Grandes Regiões e Unidades Federadas. 2000 a 2016*. [Acesso 21 jun 2016]. Disponível em: http://portalsaude.saude.gov.br/images/ pdf/2016/abril/27/tabela-casos-febre-maculosa-2016.pdf

46.Cordeiro M. Dias Raia VA, Valim JRA, Castro GNS, Souza CE, Fonseca AH. Frequência de anticorpos da classe IgG anti-Rickettsia rickettsii em equinos na Universidade Federal Rural do Rio de Janeiro, Campus Seropédica*. Rev. Bras. Med. Vet., 2015 jan/mar; 37(1):78-82.

47.Borges LMF, Silva CRF. Ixodídeos parasitos de bovinos e equinos da microrregião de Goiânia, Goiás. Rev. Parasit. Trop. 1994; 23(1):69-74.

48.Martins MEP, Sousa-Martins KC. Riquetsioses (Rickettsia spp.) transmitidas por carrapatos. Encicl. Biosf. 2014; 10(18):2735-56. [Acesso 24 jun 2016]. Disponível em: http://www.conhecer.org.br/enciclop/2014a/ AGRARIAS/riquetsioses.pdf 